Check for updates

Cite this: J. Mater. Chem. A, 2018, 6, 24330

\title{
ETFE-based anion-exchange membrane ionomer powders for alkaline membrane fuel cells: a first performance comparison of head-group chemistry $\dagger$
}

\author{
Ana Laura Gonçalves Biancolli, (DD ad Daniel Herranz, (DD ${ }^{\text {cd }}$ Lianqin Wang, (D) d \\ Gabriela Stehlíková, ed Rachida Bance-Soualhi, (D) d Julia Ponce-González, (D) d \\ Pilar Ocón, ${ }^{c}$ Edson A. Ticianelli, ${ }^{a}$ Daniel K. Whelligan, (D) John R. Varcoe (D)*d \\ and Elisabete I. Santiago (D) bd
}

\begin{abstract}
In the last few years, the development of radiation-grafted powder-form anion-exchange ionomers (AEI), used in combination with anion-exchange membranes (AEM), has led to the assembly of AEM-based fuel cells (AEMFC) that routinely yield power densities ranging between $1-2 \mathrm{~W} \mathrm{~cm}^{-2}$ (with a variety of catalysts). However, to date, only benzyltrimethylammonium-type powder AEls have been evaluated in AEMFCs. This study presents an initial evaluation of the relative AEMFC power outputs when using a combination of ETFE-based radiation-grafted AEMs and AEls containing three different head-group chemistries: benzyltrimethylammonium (TMA), benzyl-N-methylpyrrolidinium (MPY), and benzyl- $N$ methylpiperidinium (MPRD). The results from this study strongly suggest that future research should focus on the development and operando long-term durability testing of AEMs and AEls containing the MPRD head-group chemistry.
\end{abstract}

Received 27th August 2018
Accepted 29th October 2018

DOI: $10.1039 / c 8 t a 08309 f$

rsc.li/materials-a

\section{Introduction}

Fuel cells are considered an efficient and clean energy conversion technology, which can offer superior energy efficiencies to conventional technologies, such as combustion engines. Such devices have been considered promising, due to the ability to directly convert chemical energy (provided from a fuel, e.g. $\mathrm{H}_{2}$ ) into electrical energy, with wide applicability in mobile (transportation), portable, and stationary systems. ${ }^{1,2}$

In the class of low-temperature fuel cells, alkaline fuel cells (AFC) have regained relative importance due to the development of high-performance anion-exchange membranes (AEM). The main advantages of an anion-exchange membrane fuel cell (AEMFC) over current proton exchange membrane fuel cells (PEMFC) are: (i) lower activation overpotential at the cathode

${ }^{a}$ Instituto de Química de São Carlos, Universidade de São Paulo, São Carlos, Brazil ${ }^{b}$ Instituto de Pesquisas Energéticas e Nucleares - IPEN-CNEN/SP, São Paulo - SP, Brazil

${ }^{c}$ Departamento de Quimica Fisica Aplicada, Universidad Autonoma de Madrid, Madrid, Spain

${ }^{d}$ Department of Chemistry, The University of Surrey, Guildford GU2 7XH, UK. E-mail: j. varcoe@surrey.ac.uk

${ }^{e}$ Department of Inorganic Chemistry, Faculty of Natural Sciences, Comenius University, 84215 Bratislava, Slovakia

$\dagger$ Electronic supplementary information (ESI) available: Additional SEM, EDX and fuel cell data in support of the main article. See DOI: 10.1039/c8ta08309f promising the use of non-Pt-group catalysts, (ii) a less corrosive environment allowing the use of cheaper metallic components, (iii) reduced gas and alcohol crossover, and (iv) alternate water management. ${ }^{3,4}$ AEMs are ionomeric polymers, in the same way as the proton exchange membranes used in PEMFCs, but where hydroxyl ions $\left(\mathrm{OH}^{-}\right)$are ionically bound to polymer-bonded (positively charged) quaternary ammonium groups, which form the anion conducting network. ${ }^{5}$

Despite the improvements in the development of AEMs, AEMFCs have (until recently) presented poorer performances in comparison to the more well-stablished PEMFCs. One of the reasons for this is associated with the inferior $\mathrm{OH}^{-}$conductivity of many AEMs in comparison to $\mathrm{H}^{+}$conduction in PEMs; this often lead to the use of AEMs with higher IECs (ion exchange capacity), leading to the risk of additional mechanical instabilities. ${ }^{6}$ This poor AEMFC performance is also due to the unavailability of suitable anion-exchange ionomer (AEI) candidates, which are needed to impart $\mathrm{OH}^{-}$conducting in the catalyst layers of the electrodes (more on this later). The chemical, thermal and mechanical stabilities of AEMs is strongly dependent on the nature of the (anion conducting) functional groups and also the backbone chain. Besides temperature, the main cause of degradation of various anion conducting groups and polymer chains is the alkalinity of the medium (high $\mathrm{pH}$ ), a problem that is especially severe in materials containing lower hydration levels. ${ }^{7,8}$ AEMs are formed 
using a variety of backbones, including non-fluorinated, partially fluorinated or fully fluorinate polymers, such as poly(ethylene), polysulfones, poly(phenylene oxide)s (PPO), poly(phenylene)s, polybenzimidazoles (PBI), and modified poly(ethylene-co-tetrafluoroethylene) (ETFE). The covalentlylinked side-chain quaternary ammonium cationic groups are responsible for conduction of the anions $\left(\mathrm{OH}^{-}\right)$.

Such side-chains can be incorporated onto the backbone of polymer precursors by copolymerization of monomers using the radiation-grafting technique, which allows the use of prefabricated polymeric films, leading to facile AEMs production. ${ }^{9}$ The desired objective of radiation-grafting is to create active sites on the polymer chains onto which grafted polymer side-chains can be attached (when placed in contact with suitable monomers). A major advantage of this technique is that materials with different head-group chemistries can be synthesised from the same precursor polymer electrolytes with similar ion-exchange capacities (as an aside, this is demonstrated by the data presented in Fig S1 in the ESI $\uparrow$ related to the development of different imidazolium-based radiation-grafted AEMs). However, other modifications induced by polymer irradiation can occur, including undesirable scission of the backbone chain (producing mechanically weaker materials), formation of covalent cross-links, and the introduction of (reactive) unsaturated chemical groups. ${ }^{\mathbf{1 0}}$

Radiation-grafted anion-exchange polymer electrolytes have been prepared by using both simultaneous-(mutual)-irradiation or pre-irradiation induced grafting methods. In general, the simultaneous method results in the production of undesired, un-grafted homopolymers, while polymers with lower degrees of grafting are typically produced with the pre-irradiation method (often then requiring higher radiation doses that will result in more polymer damage). ${ }^{\mathbf{1 1}}$

The lack of optimised gas diffusion electrodes (GDE) for the MEA (membrane-electrode assembly), which combine ionic and electronic conductivity with efficient transport of reactants, products and water in the three-phase boundary, has impeded development of high-performance AEMFCs. ${ }^{12}$ In this context, the AEI plays an essential role on the GDE's catalyst layer (CL), with active participation in the ion transport to and from the surfaces of the electrocatalysts. ${ }^{13,14}$ The AEIs, often supplied in solution or dispersion form, combine the role of binder and $\mathrm{OH}^{-}$ion conductor in the CL. ${ }^{15}$ Similar to the AEMs, the main requirements for the use in GDE are the combination of high ion conductivity and stability in alkaline media, especially in the cathode where dry out leads to reduced conductivity and durabilities. ${ }^{16-18}$ The development of AEIs is much more early stage ( $c f$. AEMs) due to the difficulty of formulating dispersions or ionomer solutions without deterioration of their chemical properties. AEI concepts based on both cross-linked and uncross-linked polymers have been proposed, ${ }^{12,19-23}$ but their performances in AEMFCs is still poor compared to the perfluorosulfonic acid (PFSA) ionomers used in PEMFCs. Advances in AEI development are desperately required.

In 2014, Poynton et al. first reported the use of a powdered AEI in AEMFCs. ${ }^{24}$ The AEI powder was prepared by the radiation-grafting of VBC (vinylbenzyl chloride) monomer onto
ETFE powders followed by functionalisation with trimethylamine to form the quaternary ammonium forms, which can then be directly used within the CLs. Subsequently, this AEI powder has been used in combination with optimised AEMs leading to impressive AEMFC performances; ${ }^{25-29}$ this demonstrates that ionomer powders can be effectively incorporated into CLs, opening up new opportunities for high performance AEMFCs.

In this context, this article describes the synthesis and characterization of irradiated ETFE-based AEI powders (Scheme 1) that have been functionalised with three different cationic head-groups (previously only studied for radiation-grafted $\mathrm{AEMs}^{30}$ and not for AEI powders): benzyltrimethylammonium (TMA), benzyl- $N$-methylpyrrolidinium (MPY), or benzyl- $N$ methylpiperidinium (MPRD). This study will evaluate these three different types of AEI powder with respect of AEMFC power outputs (alongside their corresponding functionalised AEMs). The results from this study can then be used to direct future (time intensive and expensive) operando durability studies with down-selected head-group chemistry options. The effect of using different batches of VBC-grafted ETFE (in electrode fabrication) and repeat electrodes (with the same AEI powder batch) are also evaluated.

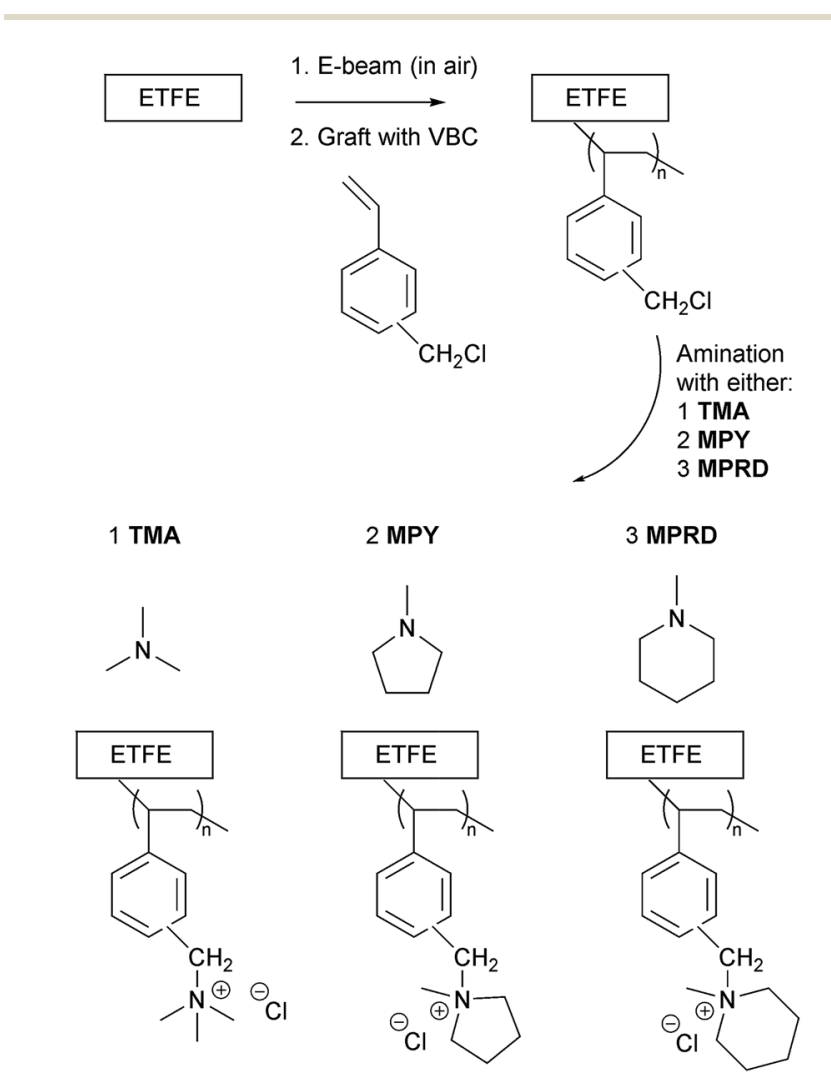

Scheme 1 An outline of the synthesis of the radiation-grafted anionexchange membranes (AEM, formed by modification of ETFE films) and powder anion-exchange ionomer (AEI, formed from ETFE powders). These are designated AEM(TMA), AEM(MPY), AEM(MPRD), AEI(TMA), AEI(MPY), and AEI(MPRD) in this article. These $\mathrm{Cl}^{-}$anion forms can be converted to other anion forms (e.g. $\left.\mathrm{OH}^{-}\right)$via an appropriate ionexchange procedure (see Materials and methods section). 
Table 1 A summary of the reaction conditions used to synthesise the AEMs in this study along with key properties of the final $\mathrm{AEMs}^{\mathrm{N}}$ in their $\mathrm{Cl}^{-}$ forms (in italics). Error bars indicate sample standard deviations of measurements conducted on $n=3$ different samples of each AEM

\begin{tabular}{|c|c|c|c|}
\hline & $\operatorname{AEM}(\mathrm{TMA})$ & $\operatorname{AEM}(\mathrm{MPY})$ & AEM(MPRD) \\
\hline Radiation dose & 30 kGy & 40 kGy & $40 \mathrm{kGY}$ \\
\hline VBC concentration & $5 \%$ vol. & $5 \%$ vol. & $5 \%$ vol. \\
\hline Amination solution (aq.) concentration & $45 \%$ vol. & $50 \%$ vol. & $15 \%$ vol. \\
\hline Amination time & $24 \mathrm{~h}$ & $16 \mathrm{~h}$ & $18 \mathrm{~h}$ \\
\hline Amination temp. & Room temp. & $70{ }^{\circ} \mathrm{C}$ & $60^{\circ} \mathrm{C}$ \\
\hline$W U(\%)^{b}$ & $67 \pm 7$ & $121 \pm 5$ & $84 \pm 8$ \\
\hline$t_{\text {hyd }} / \mu m^{c}$ & $56 \pm 3$ & $70 \pm 2$ & $55 \pm 2$ \\
\hline$t_{d e h y d} / \mu m^{d}$ & $45 \pm 2$ & $47 \pm 2$ & $43 \pm 2$ \\
\hline $\operatorname{TPS}(\%)^{e}$ & 24 & 49 & 28 \\
\hline$I P S(\%)^{f}$ & 16 & 31 & 18 \\
\hline
\end{tabular}

${ }^{a}$ The in-plane $\mathrm{Cl}^{-}$anion conductivity of the AEMs in water at $60^{\circ} \mathrm{C}$ from 4 -probe electrochemical impedance spectroscopy data. ${ }^{b} \mathrm{Gravimetric}$ water uptakes at room temperature. ${ }^{c}$ Hydrated AEM thickness at room temperature. ${ }^{d}$ Dehydrated AEM thickness at room temperature. ${ }^{e}$ Through-plane swelling $\left(=100 \times\left(t_{\text {hyd }}-t_{\text {dehyd }}\right) / t_{\text {dehyd }}\right) .{ }^{29} f$ In-plane swelling $\left(=100 \times A_{\text {hyd }}-A_{\text {dehyd }}\right) / A_{\text {dehyd }}$ where $A$ is membrane area.

\section{Materials and methods}

\section{Preparation of anion-exchange membranes (AEM)}

This work involved the synthesis of radiation-grafted AEMs based on ETFE polymer films (Nowofol, $25 \mu \mathrm{m}$ thick), which were electron-beamed in presence of air (4.5 MeV Dynamatron Continuous Electron Beam Unit, STERIS Synergy Health, South Marston, UK) with absorbed doses controlled by the number of passes (10 kGy per pass). ${ }^{\mathbf{2 4 , 2 8}}$ The ETFE films were exposed to a 30 or $40 \mathrm{kGy}$ absorbed dose and stored at $-40{ }^{\circ} \mathrm{C}$ before grafting.

The e-beam-treated ETFE films $(13 \times 13 \mathrm{~cm})$ were immersed in aqueous mixtures containing $5 \%$ vol. vinylbenzyl chloride monomer (VBC, Sigma-Aldrich product code 338729, 97\% purity, mixture of 3- and 4-isomers, no prior removal of the 700$1100 \mathrm{ppm}$ nitromethane or 50-100 ppm tert-butylcatechol inhibitors) and 1\% vol. 1-octyl-2-pyrrolidone dispersant (SigmaAldrich) in glass vessels. After the grafting mixtures were purged with $\mathrm{N}_{2}(2 \mathrm{~h})$ the vessels were sealed and heated at $70{ }^{\circ} \mathrm{C}$ for $16 \mathrm{~h}$. After grafting was complete, the films were removed and washed multiple times with toluene to remove excess unreacted VBC and any traces of VBC homopolymer that may be present. The resulting intermediate VBC-grafted films were subsequently dried at $70^{\circ} \mathrm{C}$ for $5 \mathrm{~h}$ in a vacuum oven.

The VBC-grafted films were then aminated with three different amines by immersion in aqueous solutions of various

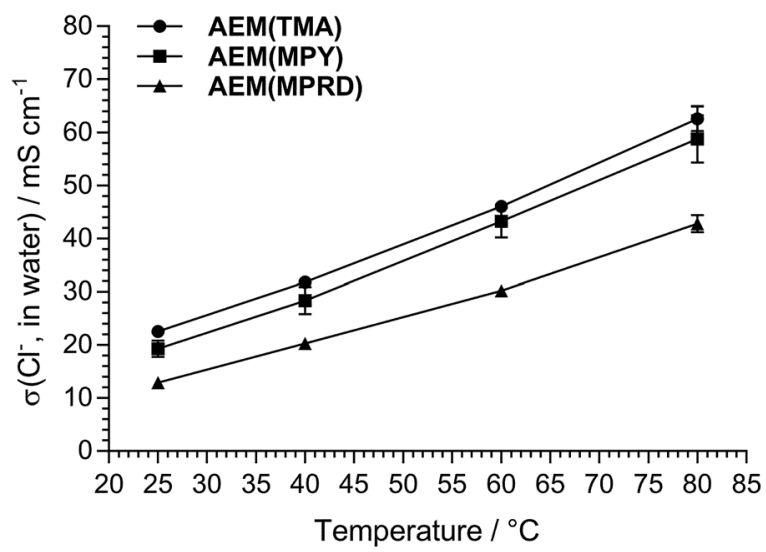

Fig. 1 A relative comparison of the $\mathrm{Cl}^{-}$anion conductivities of the AEMs used in this study (fully hydrated in water, 4-probe electrochemical impedance spectroscopy data).

concentrations for various durations (exact conditions summarised in Table 1). The amines used were trimethylamine (TMA), $N$-methylpyrrolidine (MPY) and $N$-methylpiperidine (MPRD). After amination, the resulting crude AEMs (predominantly in the $\mathrm{Cl}^{-}$anion forms) were washed multiple times with ultrapure water (UPW). They were then ion-exchange to the pure

Table 2 A summary of the reaction conditions used to synthesise the powder AEls in this study along with their IECs in the $\mathrm{Cl}^{-}$anion form (in italics). Error bars indicate sample standard deviations of measurements conducted on $n=3$ different samples of each AEl

\begin{tabular}{llll}
\hline & AEI(TMA) & AEI(MPY) & AEI(MPRD) \\
\hline Radiation dose & $100 \mathrm{kGy}$ & $100 \mathrm{kGy}$ & $100 \mathrm{kGy}$ \\
VBC concentration & $5 \%$ vol. & $5 \%$ vol. & $5 \%$ vol. \\
Graft time/temp. & $24 \mathrm{~h}$ at $60{ }^{\circ} \mathrm{C}$ & $24 \mathrm{~h}$ at $60^{\circ} \mathrm{C}$ & $24 \mathrm{~h}$ at $60{ }^{\circ} \mathrm{C}$ \\
Amination solution (aq) concentration & $45 \%$ vol. & $50 \%$ vol. & $15 \%$ vol. \\
Amination time & $24 \mathrm{~h}$ & $16 \mathrm{~h}$ & $18 \mathrm{~h}$ \\
Amination temp. & Room temp. & $50{ }^{\circ} \mathrm{C}$ & \\
IEC/mmol g & & $1.90 \pm 0.02$ & $1.99 \pm 0.01$
\end{tabular}




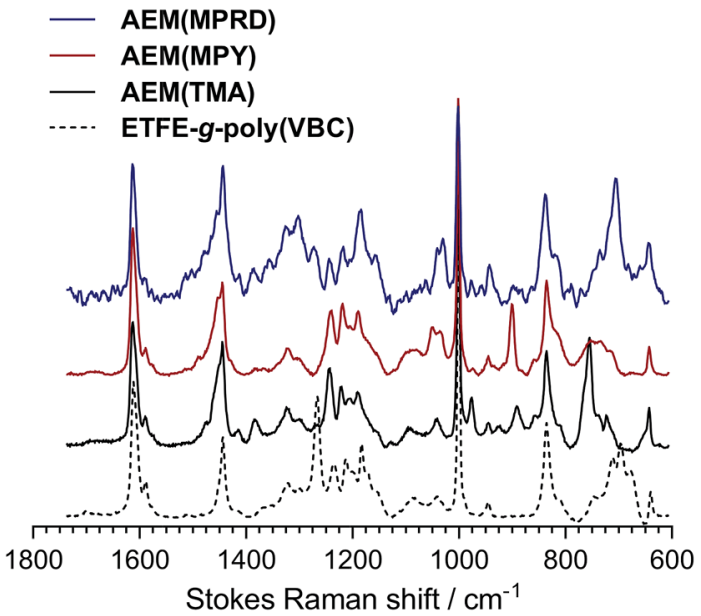

Fig. 2 The Raman spectra for the (pre-aminated) VBC-grafted ETFEfilm (ETFE-g-poly(VBC)) and the three AEMs synthesised for this study (if viewing in black and white, the legend items are in same order as the spectra). Laser $\lambda=785 \mathrm{~nm}$.

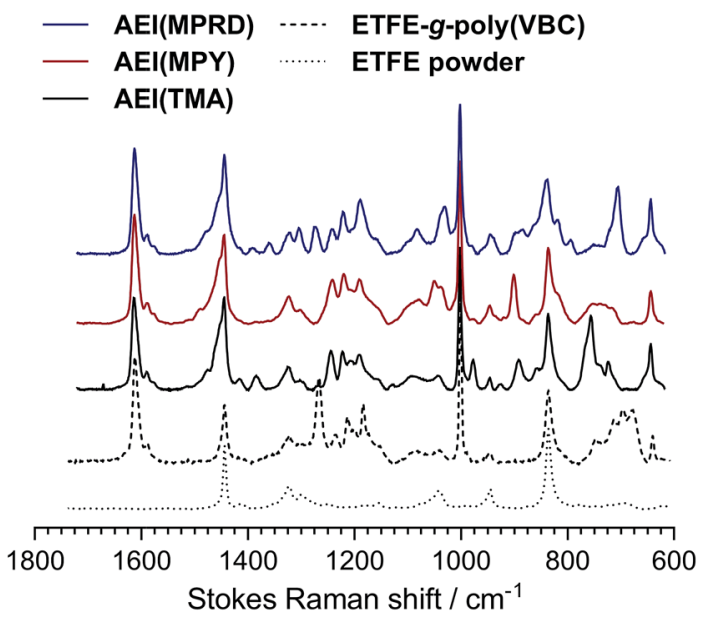

Fig. 3 The Raman spectra for the precursor (pre-irradiated) ETFE powder, the (pre-aminated) VBC-grafted ETFE-powder (ETFE-g-pol$y(V B C)$ ) and the three AEls synthesised for this study (if viewing in black and white, the order of the AEls in the legend is in the same order as the spectra). Laser $\lambda=785 \mathrm{~nm}$.

$\mathrm{Cl}^{-}$anion forms via immersion in aqueous $\mathrm{NaCl}\left(1 \mathrm{~mol} \mathrm{dm}^{-3}\right)$ overnight at room temperature (with at least 2 changes of solution during this time). The final $\mathrm{Cl}^{-}$form AEMs were obtained after rigorous washing in UPW at room temperature (ensuring no $\mathrm{Na}^{+}$co-ions and no excess $\mathrm{Cl}^{-}$counter ions were present, such that the only $\mathrm{Cl}^{-}$counter ions present were those charge balancing the positive charges on the grafted polymer chains). All AEMs were stored in UPW until required.

\section{Characterisation of the AEMs}

The AEMs were characterised in the $\mathrm{Cl}^{-}$forms using the routine procedures detailed in ref. 29 (without modification): these include the measurement of ion-exchange capacity (IEC), 4probe (in-plane) conductivities in water, and gravimetric water
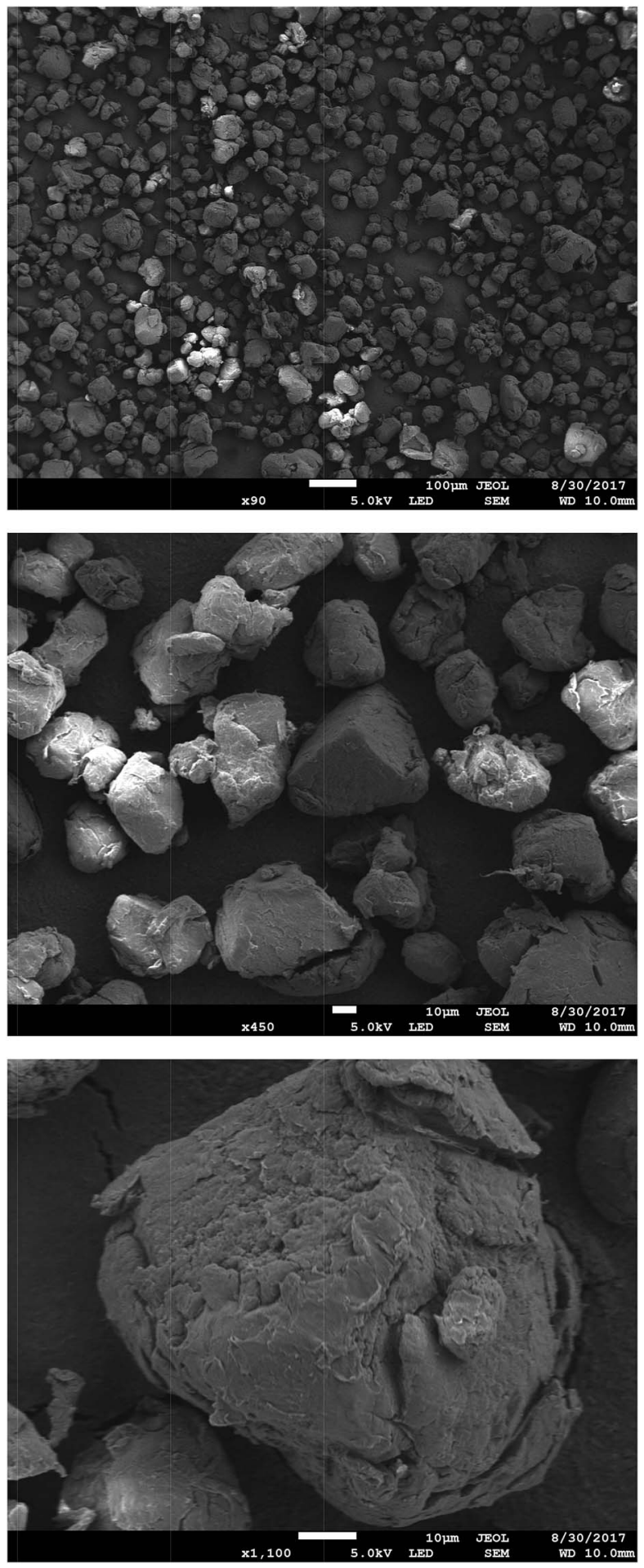

Fig. 4 SEM micrographs of the (pre-aminated) VBC-grafted ETFE powders at $\times 90, \times 450$, and $\times 1100$ magnifications (from top to bottom).

uptakes. These key properties are summarised in Table 1 . We note that the AEMs swell more in the thickness direction than in the in-plane direction: this is important for future long-term mechanical durabilities when operated in AEMFCs. Raman spectra of the VBC-grafted ETFE-films and the final AEMs were collected using Renishaw InVia Raman Spectrometer (laser $\lambda=$ $785 \mathrm{~nm}$ ) equipped with CCD and Leica microscope. 

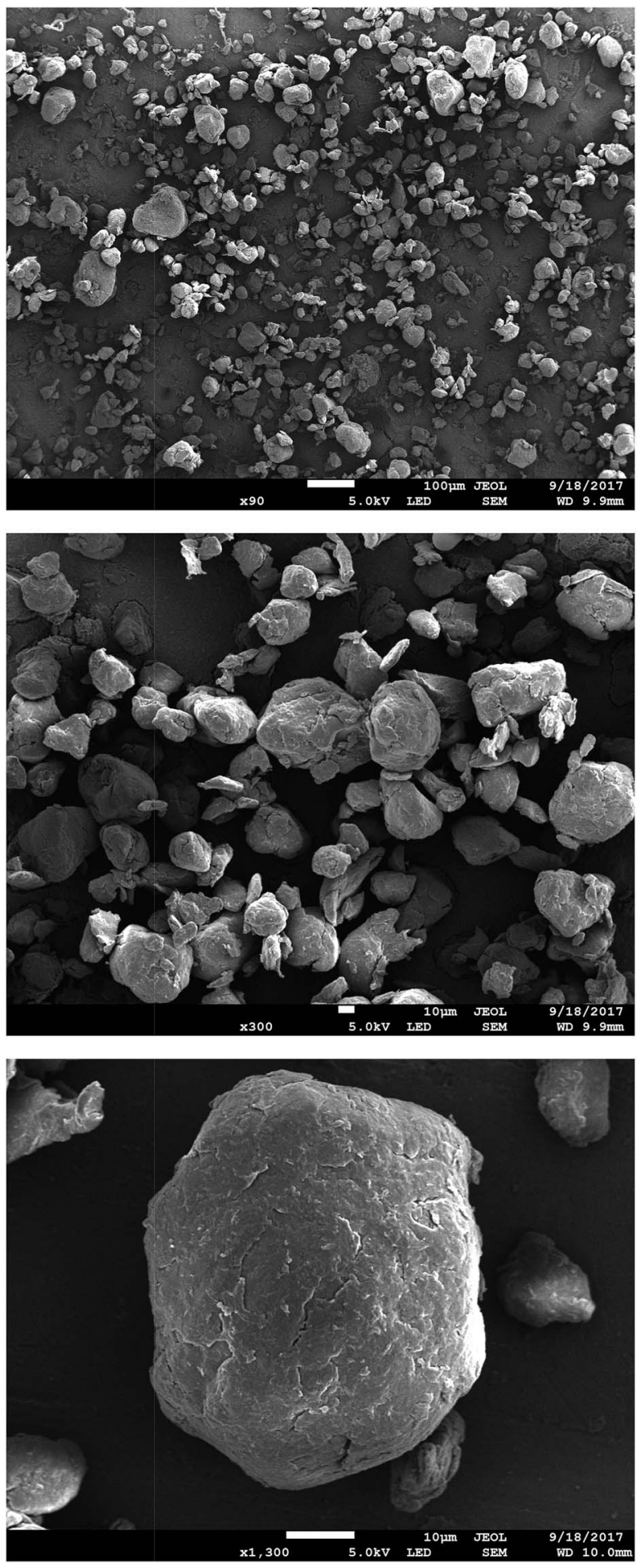

Fig. 5 SEM micrographs of AEM(TMA) at $\times 90, \times 300$, and $\times 1300$ magnifications (from top to bottom).

Preparation and initial characterisation of the powder anionexchange ionomers (AEI)

The methodology for synthesising the radiation-grafted ETFEbased powder AEIs was similar to that used for producing the AEMs above. These procedures will not be repeated in detail; however, modifications are highlighted in the following text.
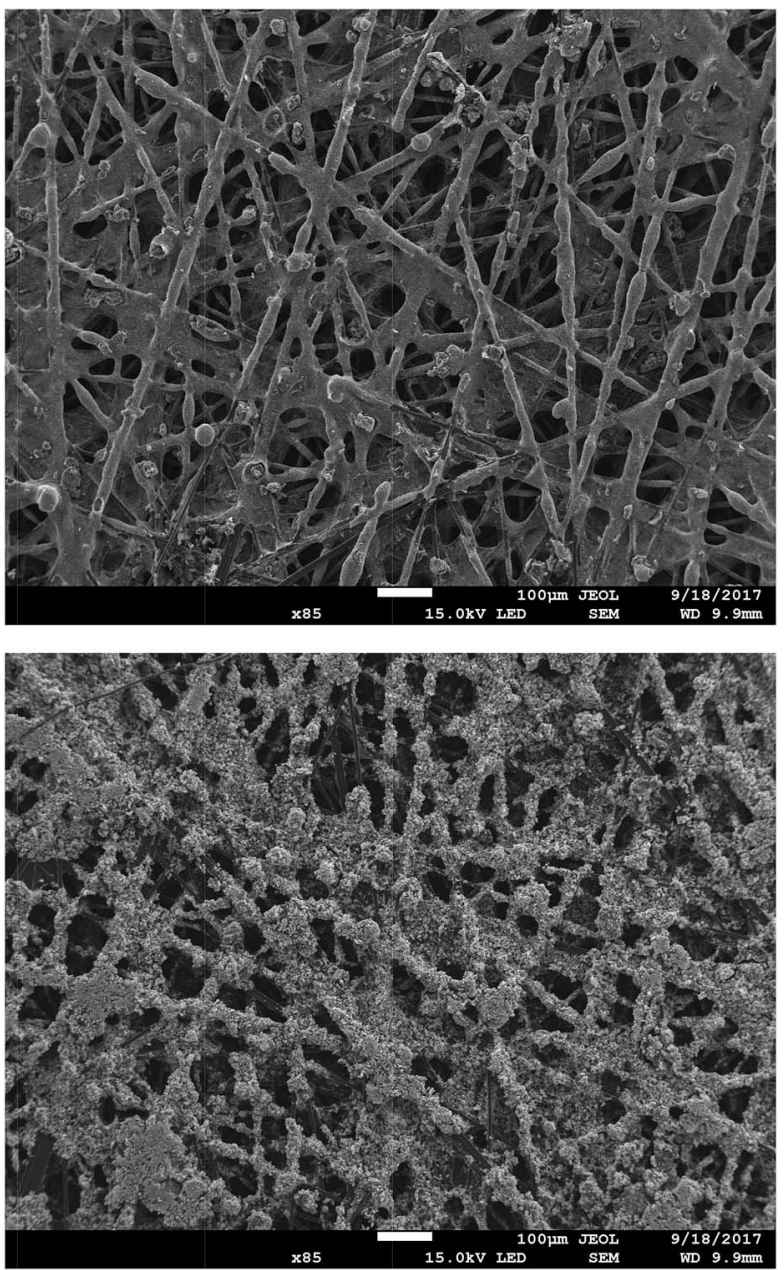

Fig. 6 SEM micrographs ( $\times 85$ magnification) of an exemplar Pt/C cathode (top) and PtRu/C anode (bottom) containing AEM(TMA) at a loading of $20 \% \mathrm{wt}$.

The ETFE powders (Fluon ${ }^{\circledR}$ Z-8820X, AGC Europe, particle diameters $20-30 \mu \mathrm{m}$ ) were irradiated in air to an absorbed dose of $100 \mathrm{kGy}$ using the same electron-beam facility. The ebeamed powders (up to $20 \mathrm{~g}$ per batch) were grafted using aqueous grafting solutions with the conditions summarised in Table 2. The resulting intermediate VBC-grafted powders were recovered by filtration, washed with toluene and subsequently dried at $50{ }^{\circ} \mathrm{C}$ for $5 \mathrm{~h}$ in a vacuum oven. The AEI powders when then aminated using the conditions summarised in Table 2. After ion-exchange to the pure $\mathrm{Cl}^{-}$anion forms and thorough washing with UPW (additional filtration steps needed to recover the modified powders) the final AEI powders were then dried in a vacuum oven at $50{ }^{\circ} \mathrm{C}$ overnight before being subjected to ball milling for $8 \mathrm{~h}$ to achieve deagglomeration of the powder particles. The IECs of the powder AEIs were recorded using exactly the same method that was used for the AEMs. ${ }^{29}$ Raman spectra of the ETFE precursor powder, the VBC-grafted powders and the final powder AEIs were collected using the same Renishaw InVia Raman spectrometer as used with the AEMs. 

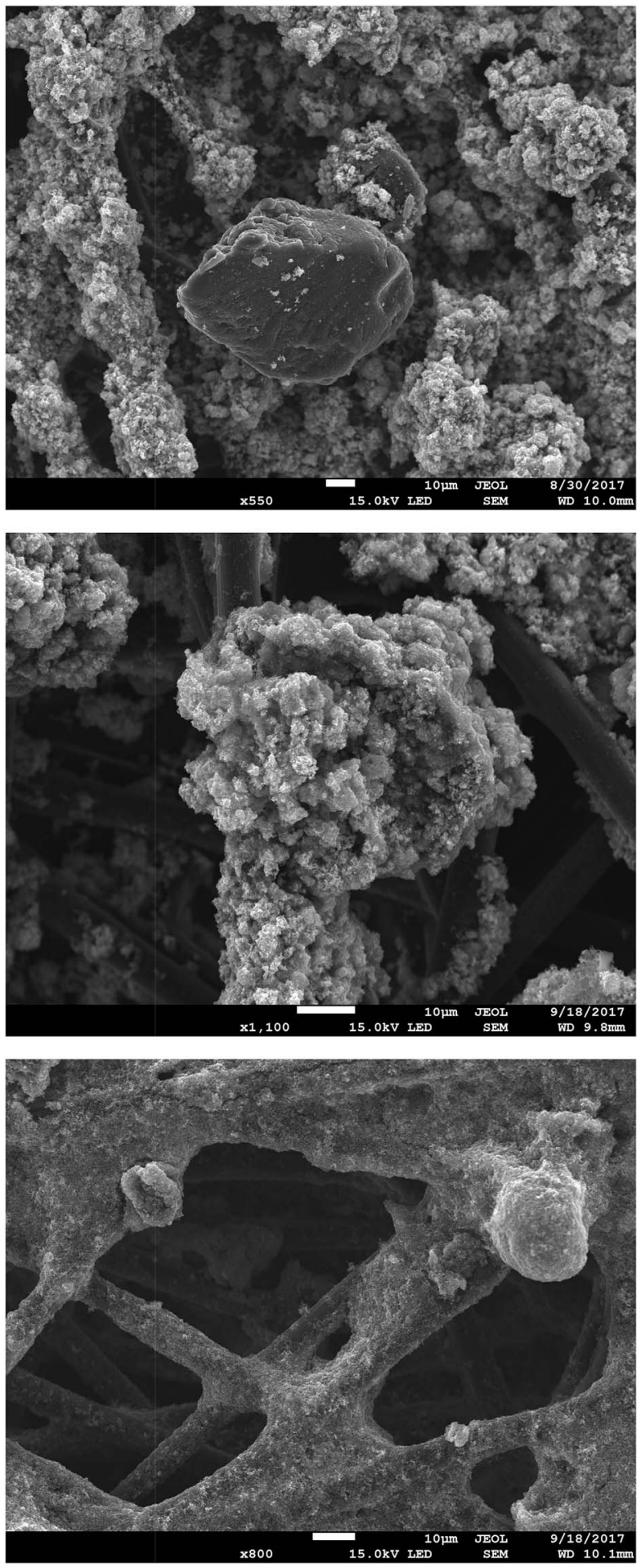

Fig. 7 SEM micrographs of: (top) an uncoated AEI(MPY) particle in a PtRu electrode ( $\times 550)$; (middle) a coated AEI(MPY) particle in a PtRu electrode $(\times 1100)$; and (bottom) the coating of AEI(MPY) particles in a $\mathrm{Pt} / \mathrm{C}$ electrode $(\times 800)$.

Scanning electronic microscopy (SEM) and energy-dispersive X-ray spectroscopy (EDX) of the powder AEIs

The powder AEIs (and the electrodes fabricate from them - see next section) were evaluated morphologically using SEM. A
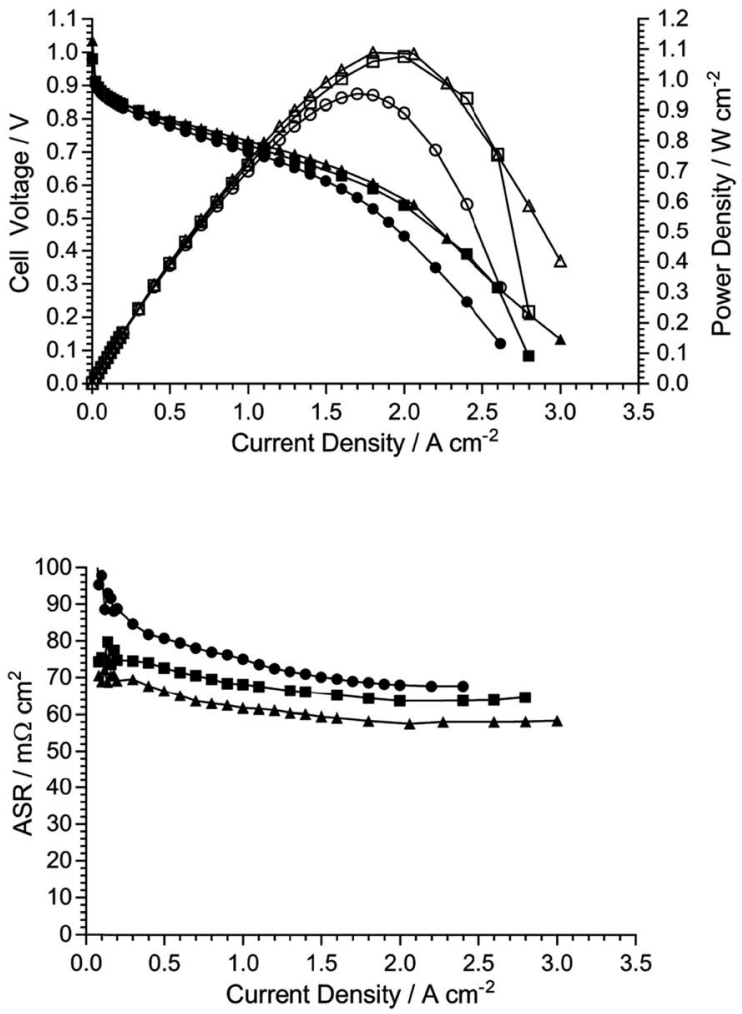

Fig. 8 AEMFC fuel cell performances at $60{ }^{\circ} \mathrm{C}\left(\mathrm{H}_{2}\right.$ anode gas and $\mathrm{O}_{2}$ cathode gas, both supplied unpressurised with dewpoint temperatures of $55^{\circ} \mathrm{C}$ ) with three repeated MEA fabrications, each containing the same TMA-based AEM (IEC $=2.05 \mathrm{mmol} \mathrm{g}^{-1}$ ) and the same TMAbased AEI (synthesised in a single batch with an IEC $=1.94 \mathrm{mmol} \mathrm{g}^{-1}$ ). $\mathrm{PtRu} / \mathrm{C}$ anodes and Pt/C cathodes were used (containing 20\% wt AEI and $0.40 \pm 0.03 \mathrm{mg} \mathrm{cm}^{-2} \mathrm{Pt}$ loadings).

small amount of each AEI (and the grafted precursor) was deposited onto a sample holder using epoxy resin and subsequently coated with Au film (9 nm thickness). The Field Emission Scanning Electron Microscopy (FE-SEM) images, and the associated EDX elemental (C, N, O, Cl, F, Pt and Ru) data, were obtained using a JEOL JSM-7100F instrument.

\section{Electrode and membrane-electrode assembly (MEA) fabrication}

The catalysed gas diffusion electrode (GDE) method was used for fabricating the AEMFC electrodes. For each cathode GDE, Pt/C (Alfa Aesar, Johnson Matthey HiSPEC 4000, 40\% wt Pt) and AEI powder (20\% wt of the total solid mass for AEI(TMA) and $30 \%$ wt for AEI(MPY) and AEI(MPRD)) were mixed together with $1 \mathrm{~mL}$ of water and $9 \mathrm{~mL}$ of propan-2-ol. This cathode catalyst ink was homogenised in ultrasound for $30 \mathrm{~min}$, sprayed onto a Toray TGP-H-60 carbon paper gas diffusion layer (GDL, non-teflonated), and then dried in air. For the anode GDEs, PtRu/C (Alfa Aesar, Johnson Matthey HiSPEC $12100,50 \%$ wt Pt and $25 \%$ wt Ru) catalyst was used as the catalyst. The geometric areas of all GDEs were $5.0 \mathrm{~cm}^{2}$ and the Pt loadings for all anodes and cathodes were $0.40 \pm 0.03$ $\mathrm{mg}_{\mathrm{Pt}} \mathrm{cm}^{-2}$. 

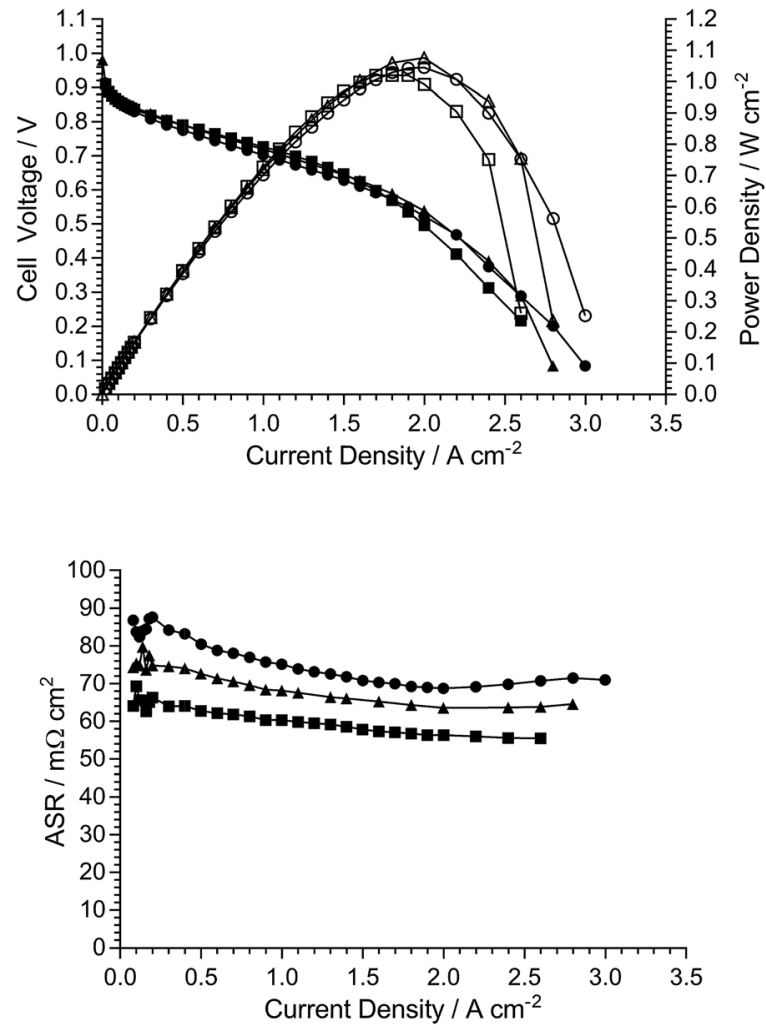

Fig. 9 AEMFC fuel cell performances at $60{ }^{\circ} \mathrm{C}\left(\mathrm{H}_{2}\right.$ anode gas and $\mathrm{O}_{2}$ cathode gas, both supplied unpressurised with dewpoint temperatures of $55^{\circ} \mathrm{C}$ ) with three MEAs fabricated using the same TMA-based AEM (IEC $=2.05 \mathrm{mmol} \mathrm{g}^{-1}$ ) but with three different batches of TMA-based AEI (IECs ranging between 1.82 and $1.94 \mathrm{mmol} \mathrm{g}^{-1}$ ). PtRu/C anodes and $\mathrm{Pt} / \mathrm{C}$ cathodes were used (containing $20 \%$ wt AEI and $0.40 \pm$ $0.03 \mathrm{mg} \mathrm{cm}^{-2}$ Pt loadings).

Prior to MEA assembly, the electrodes and AEM under test were immersed in aqueous $\mathrm{KOH}\left(1 \mathrm{~mol} \mathrm{dm}^{-3}\right)$ for $1 \mathrm{~h}$, followed by thorough washing with UPW (to remove excess $\mathrm{K}^{+}$and $\mathrm{OH}^{-}$ ions). Each membrane-electrode assembly (MEA) was assembled by placing the anode, cathode, and AEM $(4 \mathrm{~cm} \times 4 \mathrm{~cm})$, to be tested together, between two graphite plates machined with serpentine type distribution channels (the $5 \mathrm{~cm}^{2}$ fuel cell fixture used was supplied by Scribner Associates, USA) and applying a torque of $5.5 \mathrm{~N} \mathrm{~m}$. It is important to note that unlike with PEMFCs, no prior hot-pressing was used to produce the MEAs: the MEAs hot-press in situ on fuel cell start-up.

\section{Anion-exchange membrane fuel cell (AEMFC) testing}

The $\mathrm{H}_{2} / \mathrm{O}_{2}$ AEMFC tests of each MEA fabricated were conducted using an $850 \mathrm{C}$ fuel cell test station (Scribner Associates, USA). All AEMFC tests were conducted at $60{ }^{\circ} \mathrm{C}$ with $1 \mathrm{dm}^{3} \mathrm{~min}^{-1}$ gas supplies. The exact test conditions used for each test are detailed in the relevant figure captions. All gases were supplied without back-pressurisation. The AEMFCs were "activated" via operation at $0.5 \mathrm{~V}$ until a steady current was achieved (min. $1 \mathrm{~h}$ ). Polarisation curves were collected in galvanostatic mode. In situ area specific resistances (ASR) were collected using the 850C's internal current interrupt method.
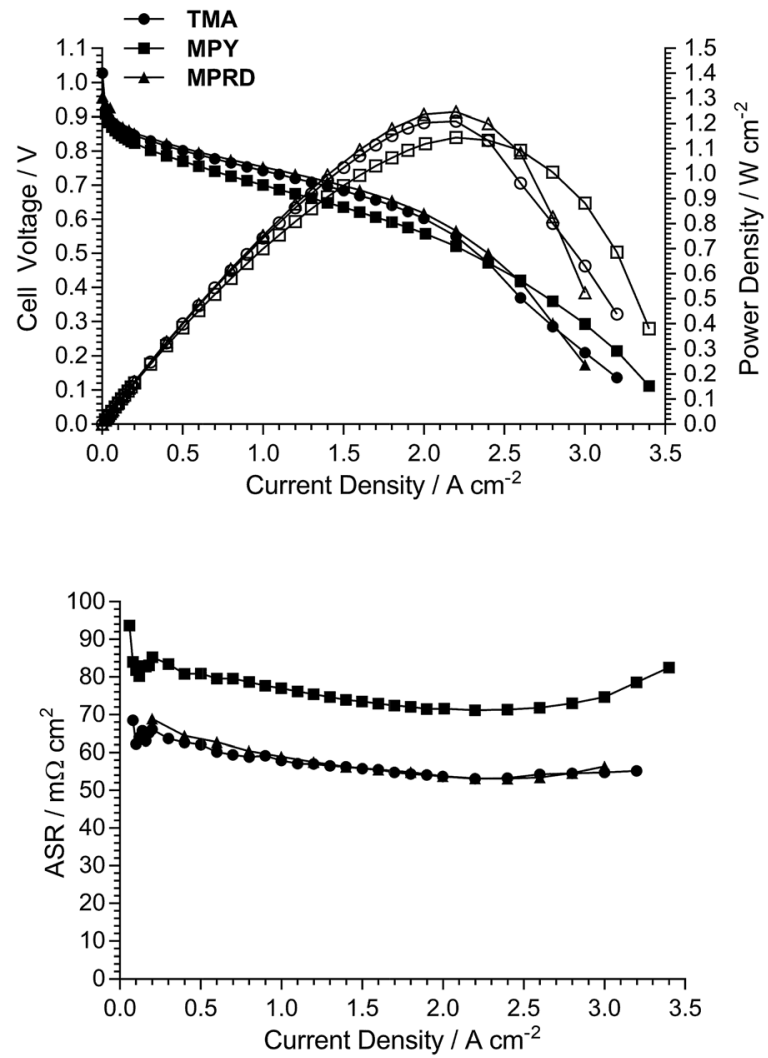

Fig. 10 AEMFC fuel cell performances at $60^{\circ} \mathrm{C}\left(\mathrm{H}_{2}\right.$ anode gas and $\mathrm{O}_{2}$ cathode gas, both supplied unpressurised with dewpoint temperatures of $60^{\circ} \mathrm{C}$ ) with three different chemistry MEAs (convention = AEl anode $/$ AEM/AEl cathode): (1) AEI(TMA)/AEM(TMA)/AEI(TMA); (2) AEI(MPY)/ AEM(MPY)/AEI(MPY); and (3) AEI(MPRD)/AEM(MPRD)/AEI(MPRD). $\mathrm{PtRu} / \mathrm{C}$ anodes and Pt/C cathodes were used (containing $20 \%$ wt $\mathrm{AEI}$ loading with AEI(TMA) and $30 \%$ wt AEI loading with AEI(MPY) and AEI(MPRD), along with $0.40 \pm 0.03 \mathrm{mg} \mathrm{cm}^{-2}$ Pt loadings).

\section{Results and discussion}

\section{Initial AEM and AEI characterisation}

As stated before, and to aid routine characterisations, ${ }^{\mathbf{1 1}}$ we always conduct initial analyses of our AEMs (for select properties) in the $\mathrm{Cl}^{-}$anion forms before they have been exposed to any extreme $\mathrm{pH}$ environments (that may subtly change their properties) and to eliminate $\mathrm{CO}_{2}$-derived interferences processes (that will change $\mathrm{OH}^{-}$forms of AEMs to $\mathrm{CO}_{3}{ }^{2-}$ / $\mathrm{HCO}_{3}{ }^{-}$forms). As such, our standard procedure for performance testing means we only convert the AEIs and AEMs into the $\mathrm{OH}^{-}$forms immediately before device testing (see AEMFC testing description above).

The IECs for the $\mathrm{Cl}^{-}$anion form AEMs and AEIs are reported in Tables 1 and 2, respectively. The IECs of the powder AEIs were similar, while the IEC of AEM(MPRD) was slightly lower than for AEM(TMA) and AEM(MPY). This contributed towards the lower conductivity profile of AEM(MPRD) across all application relevant temperatures (Fig. 1). Our previous study of thicker ETFE-based AEMs made using TMA, MPY, and MPRD (from the radiation-grafting of $50 \mu \mathrm{m}$ ETFE as opposed to the 25 $\mu \mathrm{m}$ used in this study) showed that MPRD-based radiation- 

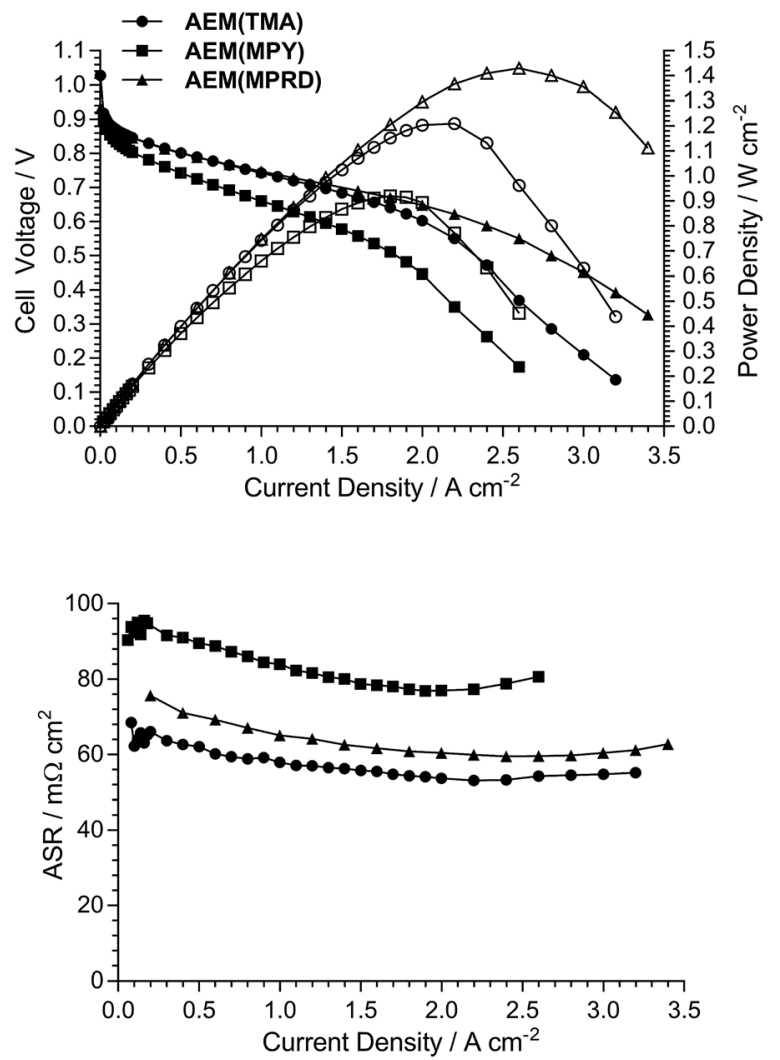

Fig. 11 AEMFC fuel cell performances at $60{ }^{\circ} \mathrm{C}\left(\mathrm{H}_{2}\right.$ anode gas and $\mathrm{O}_{2}$ cathode gas, both supplied unpressurised with dewpoint temperatures of $60^{\circ} \mathrm{C}$ ) of MEAs containing AEI(TMA) in all electrodes along with the AEMs given in the legend. $\mathrm{PtRu} / \mathrm{C}$ anodes and $\mathrm{Pt} / \mathrm{C}$ cathodes were used (containing $20 \%$ wt AEI loadings and with $0.40 \pm 0.03 \mathrm{mg} \mathrm{cm}^{-2}$ Pt loadings).

grafted AEMs intrinsically present much higher water-uptakes compared to TMA- and MPY-based AEMs. ${ }^{30}$ The use of a lower IEC for AEM(MPRD) in this study was intended to prevent an excessive water uptake and swelling, which would have led to an AEM with undesirably low mechanical properties ${ }^{\mathbf{1 1}}$ (it is the AEM, not the AEI, that is required for safe $\mathrm{H}_{2}$ and $\mathrm{O}_{2}$ gas separation characteristics inside the AEMFCs).

The Raman spectra of the AEMs are presented in Fig. 2. These spectra confirm successful synthesis as they precisely match those previously reported for the thicker ETFE-based radiation-grafted AEMs. ${ }^{30}$ Key features include the characteristic peak at $1267 \mathrm{~cm}^{-1}$ in the pre-aminated VBC-grafted ETFE films, which derives from the presence of the $-\mathrm{CH}_{2} \mathrm{Cl}$ groups on the poly(VBC) grafted chains. The disappearance of this peak in the spectra of each of the AEMs indicates successful amination (conversion of the $-\mathrm{CH}_{2} \mathrm{Cl}$ groups into the various quaternary ammonium groups). Amination is confirmed by the appearance of characteristic peaks at $756 \mathrm{~cm}^{-1}, 901 \mathrm{~cm}^{-1}$ and $705 \mathrm{~cm}^{-1}$ due to the presence of the quaternary ammonium head-groups for AEM(TMA), AEM(MPY), AEM(MPRD), respectively. All spectra contain peaks at $c a .1612 \mathrm{~cm}^{-1}$ (aromatic ring vibrations), $1001 \mathrm{~cm}^{-1}$ (due to the meta-disubstituted aromatic ring component of the grafted poly(VBC) chains), and $835 \mathrm{~cm}^{-1}$ (due
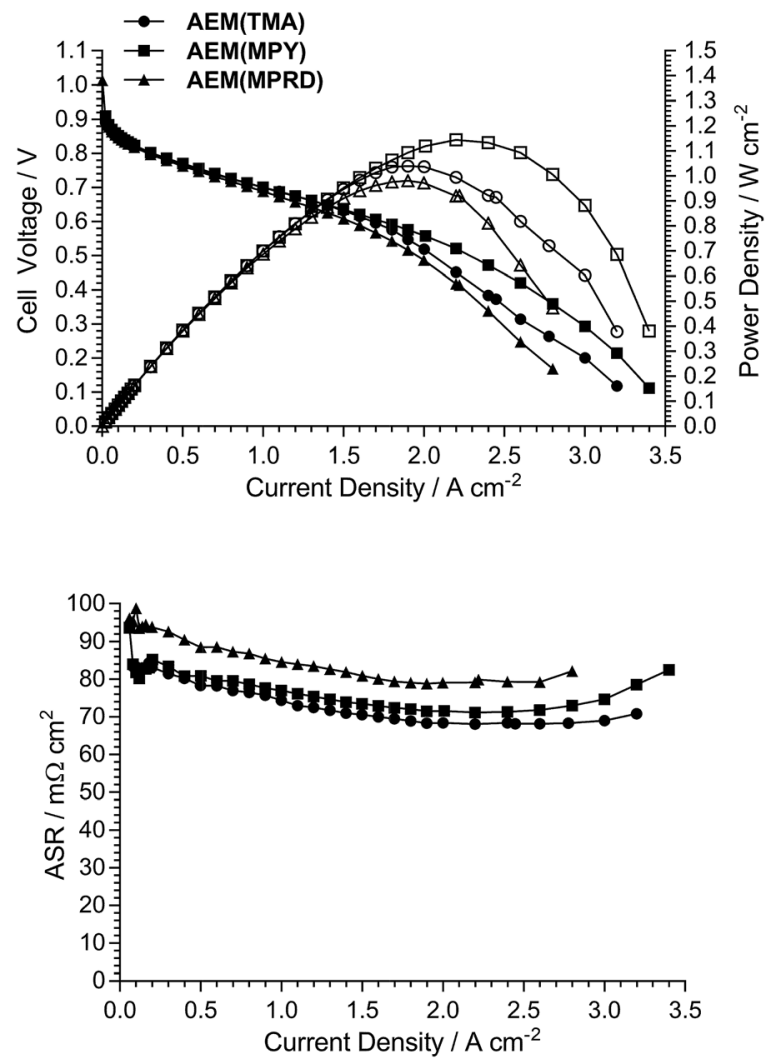

Fig. 12 AEMFC fuel cell performances at $60{ }^{\circ} \mathrm{C}\left(\mathrm{H}_{2}\right.$ anode gas and $\mathrm{O}_{2}$ cathode gas, both supplied unpressurised with dewpoint temperatures of $60^{\circ} \mathrm{C}$ ) of MEAs containing AEI(MPY) in all electrodes along with the AEMs given in the legend. $\mathrm{PtRu} / \mathrm{C}$ anodes and $\mathrm{Pt} / \mathrm{C}$ cathodes were used (containing $30 \%$ wt AEI loadings and with $0.40 \pm 0.03 \mathrm{mg} \mathrm{cm}^{-2}$ Pt loadings).

to the presence of ETFE $-\mathrm{CF}_{2}-$ groups). The Raman spectra of the ETFE-based radiation-grafted powder AEIs are highly similar with all the above-mentioned features (Fig. 3). This, alongside the measurable IECs, confirms successful synthesis of the powder AEIs.

\section{SEM and EDX analysis of the powder AEIs and electrodes}

Fig. 4 presents SEM micrographs of the VBC-grafted ETFE powder before it was reacted with the amines. The powder particles show irregular morphology with particle diameters generally in the range $20-50 \mu \mathrm{m}$. The precursor ETFE powder particles range from $20-30 \mu \mathrm{m} .{ }^{31}$ This shows that grafting did not have an excessive effect on powder particle sizes. On amination with TMA (and subsequent ball milling) the inhomogeneity in particle shape and size (ranging $10-70 \mu \mathrm{m}$ ) increases as shown in Fig. 5. Large inhomogeneities were also observed for AEI(MPY) and AEI(MPRD) (Fig. S2 in the ESI $\dagger$ ).

The powder AEIs were incorporated into cathodes (containing $\mathrm{Pt} / \mathrm{C}$ electrocatalyst) and anodes (containing $\mathrm{PtRu} / \mathrm{C}$ ). $20 \%$ wt ionomer was used in the AEI(TMA) electrodes, while $30 \%$ wt ionomer was used with AEI(MPY) and AEI(MPRD). These loadings were from AEMFC test optimisation studies (see later). SEM micrographs of sample areas of an electrode of each 

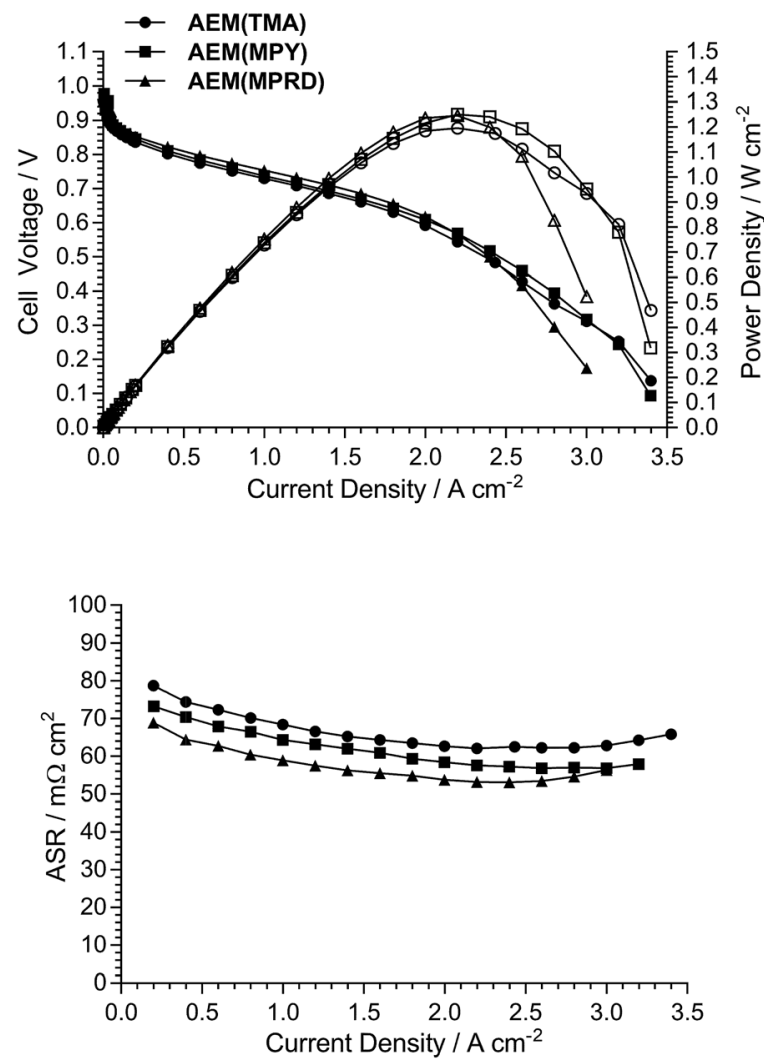

Fig. 13 AEMFC fuel cell performances at $60^{\circ} \mathrm{C}\left(\mathrm{H}_{2}\right.$ anode gas and $\mathrm{O}_{2}$ cathode gas, both supplied unpressurised with dewpoint temperatures of $60{ }^{\circ} \mathrm{C}$ ) of MEAs containing AEI(MPRD) in all electrodes along with the AEMs given in the legend. PtRu/C anodes and Pt/C cathodes were used (containing 30\% wt AEI loadings and with $0.40 \pm 0.03 \mathrm{mg} \mathrm{cm}^{-2}$ Pt loadings).

type are presented in Fig. 6 (for AEI(TMA)) and Fig. S3 in the $\mathrm{ESI} \dagger$ (for all powder AEIs). As the powder AEIs are $\mu \mathrm{m}$-sized but the electrocatalysts are nanoparticles $(<100 \mathrm{~nm}$ in size) these micrographs cannot give much of a visual indication of the exact morphology of the Pt and PtRu electrocatalyst particles. However, the AEI particles clearly form a denser coverage with the AEI(MPY)- and AEI(MPRD)-containing electrodes (due to the higher ionomer loadings used). A rougher morphology is seen for the $\mathrm{PtRu} / \mathrm{C}$-containing anodes compared to the $\mathrm{Pt} / \mathrm{C}-$ containing cathodes (with all three AEIs). As no microporous layer (MPL) was used (with this class of powder AEI, the use of an MPL appears to lead to lower AEMFC performances) the polymer-catalyst agglomerates are attached directly onto the carbon-fibres of the Toray carbon-paper GDL (with a degree of penetration into the GDL).

On closer inspection, there is evidence of both the $\mathrm{Pt} / \mathrm{C}$ and $\mathrm{PtRu} / \mathrm{C}$ catalysts coating the AEI particles and the carbon-fibres of the Toray paper electrodes (Fig. 7 shows some higher magnification SEM micrographs of sample areas of AEI(MPY) containing electrodes). There is also evidence of a proportion of AEI particles (and carbon-fibres) that are not coated with electrocatalyst. Fig. S4-S6 (in the ESI†) show the EDX analysis of different regions on several exemplar electrodes. This EDX
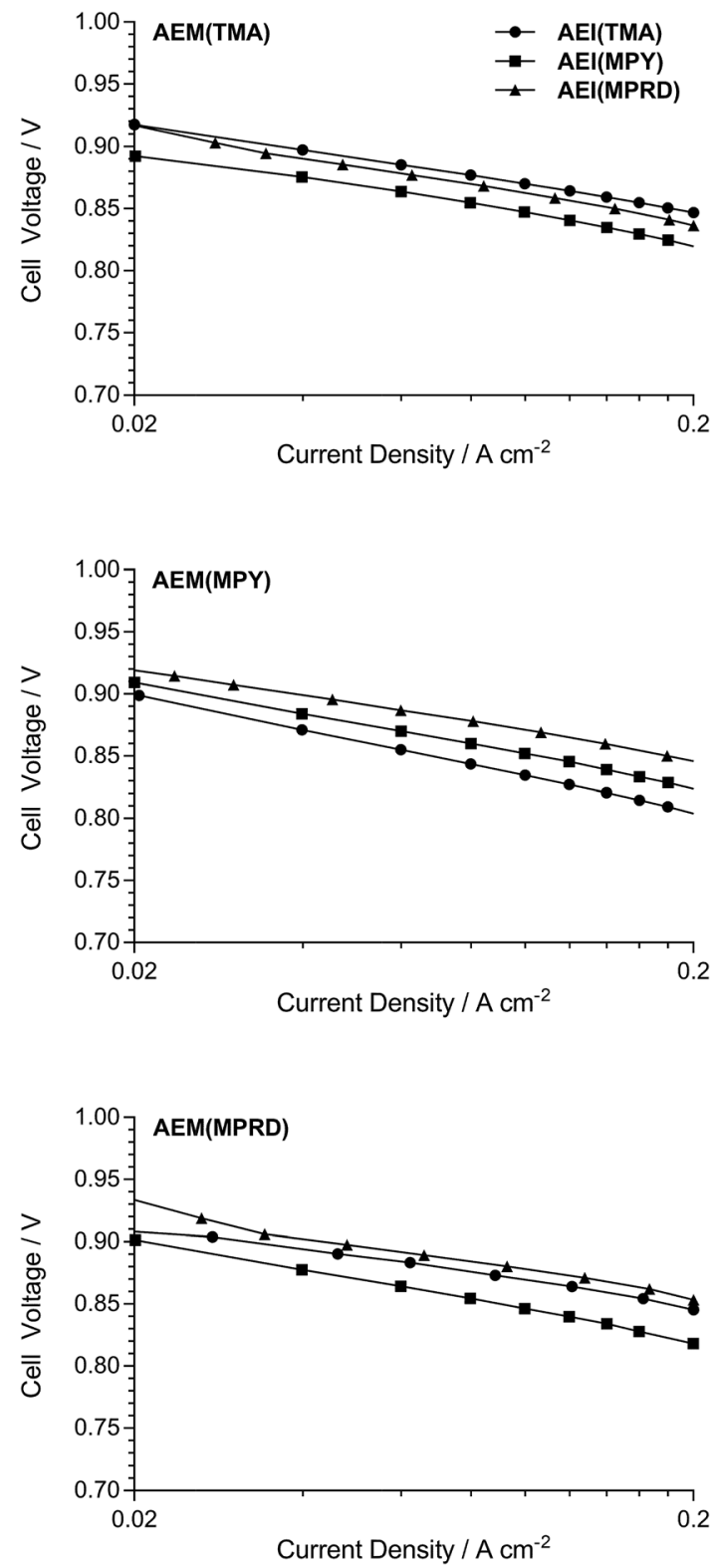

Fig. 14 Cell potential vs. $\log _{10}$ (current density) plots for the data extracted from Fig. 11-13 between 0.02 and $0.2 \mathrm{~A} \mathrm{~cm}^{-2}$.

analysis confirms that the electrodes contain a poor distribution of $\mathrm{C}$ (from the Toray paper and the carbon-support of the electrocatalysts), F (from the AEI), and metals (Pt and $\mathrm{Ru}$ ).

The morphology of these AEMFC electrodes is clearly different to that found in PEMFC based electrodes, which contain uniform distributions of ionomer and electrocatalyst. ${ }^{32}$ However, numerous studies have proven that these AEMFC electrodes (containing TMA-based radiation-grafted powder AEIs) can produce high AEMFC power performances. ${ }^{11,25-27,29,33}$

\section{AEMFC test data (repeatability)}

As the electrodes are hand sprayed, and before investigation of the effect of the different quaternary ammonium chemistries, initial experiments were conducted to evaluate the repeatability 

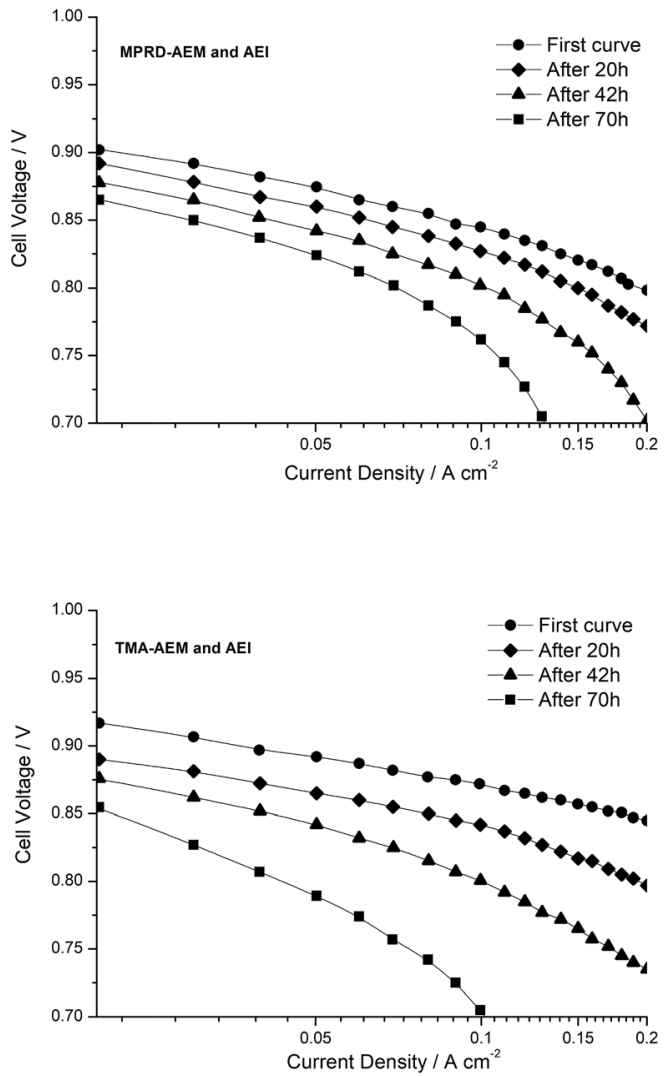

Fig. 15 Changes in the quasi-Tafel plots extracted from $\mathrm{H}_{2} / \mathrm{O}_{2}$ AEMFC tests at $60^{\circ} \mathrm{C}$, with MPRD-(top) and TMA (bottom) MEAs, both before and after cell discharge at $0.70 \mathrm{~V}$ for increasing periods of time (PtRu/C anodes and $\mathrm{Pt} / \mathrm{C}$ cathodes)

of electrode preparation. Two types of repeatability tests were conducted: (1) Fig. 8 shows the AEMFC fuel cell performances of three repeat MEAs fabricated using the same TMA-based AEM and powder AEI (from a single batch), and (2) Fig. 9 shows the AEMFC fuel cell performances of three MEAs fabricated using the same TMA-based AEM and three different batches of powder AEIs fabricated using the same synthetic protocol.

As can be seen from this data, there is a small amount of variation in peak power density: mean $=1.04 \mathrm{~W} \mathrm{~cm}^{-2}$ and sample standard deviation $=0.05 \mathrm{~W} \mathrm{~cm}^{-2}$ (range $=0.95-1.09 \mathrm{~W}$ $\mathrm{cm}^{-2}$ ) across the $n=5$ tests conducted (one of the performance curves in Fig. 9 is common with a curve in Fig. 8). As expected, due to the hand fabrication nature of the MEAs, the main differences in performance were due to variances in masstransport limitations (in the high current density region); variances in electrocatalytic performances (low current density region) and ohmic losses (medium current density region) were less significant. Considering the above, and to aid the relative comparison of AEM/AEI chemistries in AEMFC performance tests (discussed in the next section), the criterion used for the purpose of this study was that MEAs were deemed to have varied in AEMFC performance if their peak power performances were different by $>0.10 \mathrm{~W} \mathrm{~cm}^{-2}$.

\section{AEMFC test data (chemistries)}

Fig. 10 presents AEMFC test data with three different MEAs where the AEI and AEM in each MEA contain the same quaternary ammonium chemistry (e.g. an MEA containing AEI(TMA) in both electrodes along with AEM(TMA)). It is clear that changing the quaternary ammonium chemistry did not lead to significant differences in AEMFC performance with the use of MEAs in this configuration (containing only one quaternary ammonium chemistry per MEA). Note that $30 \% \mathrm{wt}$ of ionomer was used with the AEI(MPY)- and AEI(MPRD)containing MEAs, while $20 \%$ wt ionomer was used with the AEI(TMA)-containing MEA, in response to initial studies of AEI loading with each chemistry (Fig. S7-S9 in the ESI†). These loadings are used throughout the rest of this study.

Subsequent experiments involved the comparison of electrodes fabricating using each AEI in MEAs containing the different AEMs. Note this study only considers MEAs that contain the same AEI in each electrode: a study into the use of MEAs containing different AEIs in each electrode is planned for the future. Fig. 11 shows the data collected with MEAs containing AEI(TMA)-based electrodes. The variances in peak power densities are large with the use of the different AEM chemistries. The MEA containing AEM(MPRD) yielded the highest power density (of this entire study): $1.43 \mathrm{~W} \mathrm{~cm}^{-2}$ (at 2.6 $\mathrm{A} \mathrm{cm}{ }^{-2}$, ASR $=60 \mathrm{~m} \Omega \mathrm{cm}^{2}$ ). The differences in performances were primarily due to differences in in situ ohmic losses and mass transport losses. Considering that AEM(MPRD) had the lowest $e x$ situ conductivity, this result is surprising; this highlights the importance of recording in situ performances in AEMFC tests, which suggest, here, that AEM(MPRD) has faster water transport characteristics that lower mass transport losses.

Fig. 12 and 13 show the analogous AEMFC test data using electrodes containing AEI(MPY) and AEI(MPRD), respectively. The relative differences in performances with the three different AEM chemistries is less clear cut when using these cyclicquaternary-ammonium-based powder AEIs (peak power densities ranged from 0.99 to $1.25 \mathrm{~W} \mathrm{~cm}^{-2}$ over the $n=6$ experiments presented). The performance variations were again primarily due to differences in mass transport losses. The most interesting (take home) finding was that the AEI(MPRD)-based electrodes were particularly insensitive to the AEM chemistry used and produced the highest peak power densities of the cyclic-quaternary ammonium-based AEIs.

Fig. 14 shows quasi-Tafel-plots (extracted from the data presented in Fig. 11-13), comparing the fuel cells responses for each AEM combined with each AEI. These results show that the Tafel lines are all generally parallel indicating that Tafel slopes do not significantly vary with AEI chemistry (with the same catalysts used in all cases). This implies that the reaction mechanisms and rate determining steps (for both the hydrogen oxidation reaction on $\mathrm{PtRu} / \mathrm{C}$ and the oxygen reduction reaction on $\mathrm{Pt} / \mathrm{C}$ ) are not being affected by the different AEI chemistries in any major way. This behaviour is consistent with the high local $\mathrm{OH}^{-}$anion concentration in both the anode and cathode environments that may surpass any specific activity effects due to the AEI chemistry. However, the consistently high cell 
potentials observed with the use of AEI(MPRD) in the electrodes indicates that this AEI generally leads to better electrocatalysis; this could either be due to an enhanced number of active sites or an increase in exchange current densities for one or both reactions.

\section{Initial in situ, short-term stability testing}

The ex situ alkali stability tests for TMA-, MPY- and MPRD-AEMs have been reported previously. ${ }^{30}$ Due to the higher hydration levels related to the MPY and MPRD head-group chemistries, these exhibited higher alkali stabilities compared to the benchmark TMA chemistry (e.g. $17-18 \%$ loss in IEC when treated in aqueous $\mathrm{KOH}\left(1 \mathrm{~mol} \mathrm{dm}{ }^{-3}\right)$ for $28 \mathrm{~d}$ at $80{ }^{\circ} \mathrm{C}$ compared to $30 \%$ loss for the TMA-based AEM).

However, besides leading to promising fuel cell performances, MPRD-based polymer electrolytes need to be more stable under operando conditions. As an initial move towards this, we conducted comparative, short-term AEMFC tests with the TMA- and MPRD-based MEAs (each MEA contained the same chemistry in all polymer electrolyte components). Fig. 15 presents the quasi-Tafel plots for these two fuel cells: data was collected immediately after cell start up, and then after 20, 42 and $70 \mathrm{~h}$ of AEMFC discharge at $0.7 \mathrm{~V}$ and at $60{ }^{\circ} \mathrm{C}(88 \%$ and $92 \% \mathrm{RH}$ for the $\mathrm{H}_{2}$ anode and the $\mathrm{O}_{2}$ cathode respectively).

In all cases the low current density (catalyst activation) region showed a decay in performance as a function of AEMFC discharge time, which relates to a loss of catalyst activity or electrochemical active area (ECSA). For the MPRD-MEA (Fig. 15a), this loss was $c a .37 \mathrm{mV}$ between the initial performance and that observed after $70 \mathrm{~h}$ of cell discharge: in contrast this loss was $70 \mathrm{mV}$ for the TMA-MEA (Fig. 15b). Large changes in ECSA have recently been reported for a Pt/C catalyst in aqueous $\mathrm{NaOH}\left(0.1 \mathrm{~mol} \mathrm{dm}^{-3}\right)$ alkaline electrolyte during accelerated cyclic voltammetric stress tests at $25{ }^{\circ} \mathrm{C}:{ }^{34}$ after 150 cycles $\left(100 \mathrm{mV} \mathrm{s}^{-1}\right.$, between 0.1 to $1.23 \mathrm{~V}$, total test duration of 1 h) a loss of $60 \%$ ECSA was observed. This prior observation indicates that catalyst degradations contribute towards the changes in performances reported in Fig. 15, which highlights the need to develop catalysts with stabilities tailored towards operation in AEMFCs.

After several days of AEMFC discharge time, the quasi-Tafel plots tended to curve down at higher current densities (but still at current densities that are below those that cause diffusion limitations): this is characteristic of an increase in ohmic losses, which may be due to a combination of detachment of catalyst from the C-supports, ${ }^{34}$ and degradation of the anion-exchange polymer electrolyte components. Several prior works have stressed the difficulties in achieving optimized water balance in AEMFCs; $;^{25,35-37}$ the drying out of part of the MEAs in AEMFCs risks AEM/AEI degradation. The use of AEM(MPRD), as already discussed, facilitates better water management and consequently the rate of ohmic resistance increase would be expected to be lower than with the use of AEM(TMA), which is observed in the data presented in Fig. 15.

Overall, the operando voltage decays observed in Fig. 15 cannot be wholly attributed to AEI or AEM degradation. This scenario further highlights that more effort is required to determine the predominant source of operando stability. Considering issues with accessing test equipment and the length of time that such experiments take, such testing can only be rigorously conducted once suitable AEI-AEM combinations are identified. The results reported in this study represent the first step towards achieving this.

\section{Conclusions and future directions}

This study involved the development of ETFE-based radiationgrafted anion-exchange ionomer (AEI) powders containing different head-group chemistries made using trimethylamine (TMA), $N$-methylpyrrolidine (MPY), and $N$-methylpiperidine (MPRD) amination agents. These AEIs were used to form membrane electrode assemblies (MEA) containing anionexchange membranes (AEM) with the same chemistries. The resulting anion-exchange membrane fuel cell (AEMFC) performance tests on these MEAs showed that all the head-group chemistries yielded excellent AEMFC performances at $60{ }^{\circ} \mathrm{C}$. The key finding of this study was that the MPRD-based materials showed particularly notable characteristics related to the power outputs of the AEMFCs.

Our previous study on ETFE-based radiation-grafted AEMs containing the TMA-, MPY-, and MPRD-based chemistries showed that MPRD-containing (and MPY-containing) materials have higher alkali stabilities (when hydrated) compared to TMAbased materials. ${ }^{30}$ The combination of this prior finding with the AEMFC findings in this study strongly suggests that further detailed investigation of MPRD-based radiation-grafted AEMs and AEIs is warranted. However, as recently discovered (subsequent experiments that were chronologically conducted after those presented in this paper), replacing the ETFE-based AEMs with LDPE-AEMs leads to more mechanically robust AEMs (it is the mechanical weakness of the ETFE-based AEMs that limits AEMFC testing to $\left.60{ }^{\circ} \mathrm{C}\right) .{ }^{38} \mathrm{We}$ are now investigating the use of these powder AEIs in combination with LDPE-based AEMs (including MPRD versions); now that the highest performing AEI- and AEM-chemistry has been identified, these studies involving the more robust LDPE-based AEMs will include in situ durability testing at $80{ }^{\circ} \mathrm{C}$ (not achievable with ETFE-based AEMs).

\section{Author contributions}

Most of the test results were collected by ALGB, who also synthesised and characterised AEI(TMA) and AEI(MPY), with assistance from EIS (whose preliminary experiments on AEI synthesis and loadings guided this study). The MPRD-based materials were synthesised and characterised by DH. AEM(TMA) and AEM(MPY) materials were produced and characterised by LQW and RBS, respectively. EAT assisted with the data collection and analyse for Fig. 14 and 15. The choice of head-group chemistry was directed by JPG's work and guidance. GS's results were essential in justifying the use of the radiationgrafted method for this study (Fig. S1 $\dagger$ ). All other authors made contributions towards project direction, data analysis and 
manuscript preparation. JRV was responsible for overall project supervision and made a substantial contribution towards the drafting of the article.

\section{Conflicts of interest}

There are no conflicts to declare.

\section{Acknowledgements}

The research was funded by the Engineering and Physical Sciences Research Council (EPSRC grants EP/M014371/1, EP/ M022749/1, and EP/M005933/1). ALGB's exchange was funded by FAPESP grants 2016/13277-9 and 2015/09210-3, while EIS' exchange was funded by FAPESP grants 2015/23621-6, 2014/ 09087-4 and 2014/50279-4. DH's student-exchange was funded by a PDIF Short Stay Scholarship of the Autonomous University of Madrid. GS' 2015 exchange was funded by the ERASMUS+ work placement scheme.

\section{References}

1 P. P. Kundu, V. Sharma and Y. G. Shul, Crit. Rev. Solid State Mater. Sci., 2007, 32, 51-66.

2 Z. P. Cano, D. Banham, S. Ye, A. Hintennach, J. Lu, M. Fowler and Z. Chen, Nat. Energy, 2018, 3, 279-289.

3 Fuel Cell Systems Explained, ed. J. Larmine and A. Dick, 2nd edn, John Wiley \& Sons, 2003.

4 T. Zhou, R. Shao, S. Chen, X. He, J. Qiao and J. Zhang, J. Power Sources, 2015, 293, 946-975.

5 A. Brouzgou, A. Podias and P. Tsiakaras, J. Appl. Electrochem., 2013, 43, 119-136.

6 J. Pan, C. Chen, L. Zhuang and J. Lu, Acc. Chem. Res., 2012, 45, 473-481.

7 B. Gupta and G. Scherer, Chimia, 1994, 48, 127-137.

8 U. Lappan, U. Geißler, U. Gohs and S. Uhlmann, Macromolecules Materials and Engineering, 2009, 294, 510515.

9 M. Mamlouk, J. A. Horsfall, C. Williams and K. Scott, Int. J. Hydrogen Energy, 2012, 37, 11912-11920.

10 L. Gubler, Adv. Energy Mater., 2014, 4, 1300827.

11 L. Wang, J. J. Brink, Y. Liu, A. M. Herring, J. Ponce-González, D. K. Whelligan and J. R. Varcoe, Energy Environ. Sci., 2017, 10, 2154-2167.

12 X. Gao, H. Yu, J. Jia, J. Hao, F. Xie, J. Chi, B. Qin, L. Fu, W. Song and Z. Shao, RSC Adv., 2017, 7, 19153-19161.

13 J. R. Varcoe, R. C. T. Slade and E. Lam How Yee, Chem. Commun., 2006, 1428-1429.

14 D. Yang, H. Yu, G. Li, Y. Zhao, Y. Liu, C. Zhang, W. Song and Z. Shao, J. Power Sources, 2014, 267, 39-47.

15 J. R. Varcoe, P. Atanassov, D. R. Dekel, A. M. Herring, M. A. Hickner, P. A. Kohl, A. R. Kucernak, W. E. Mustain, K. Nijmeijer, K. Scott, T. Xu and L. Zhuang, Energy Environ. Sci., 2014, 7, 3135-3191.

16 S. Gu, R. Cai, T. Luo, Z. Chen, M. Sun, Y. Liu, G. He and Y. Yan, Angew. Chem., Int. Ed., 2009, 48, 6499-6502.
17 J. Pan, C. Chen, L. Zhuang and J. Lu, Acc. Chem. Res., 2012, 45, 473-481.

18 J. Pan, S. Lu, Y. Li, A. Huang, L. Zhuang and J. Lu, Adv. Funct. Mater., 2010, 20, 312-319.

19 L. Zeng and T. S. Zhao, Electrochem. Commun., 2012, 34, 278281.

20 L. Zeng, T. S. Zhao, L. An, G. Zhao, H. X. Yan and C. Y. Jung, J. Power Sources, 2015, 275, 506-515.

21 M. S. Shin, Y. J. Byun, Y. W. Choi, M. S. Kang and J. S. Park, Int. J. Hydrogen Energy, 2014, 39, 16556-16561.

22 Y. Leng, L. Wang, M. A. Hickner and C. Y. Wang, Electrochim. Acta, 2015, 152, 93-100.

23 L. Sun, J. Guo, J. Zhou, Q. Xu, D. Chu and R. Chen, J. Power Sources, 2012, 202, 70-77.

24 S. D. Poynton, R. C. T. Slade, T. J. Omasta, W. E. Mustain, R. Escudero-Cid, P. Ocón and J. R. Varcoe, J. Mater. Chem. A, 2014, 2, 5124-5130.

25 T. J. Omasta, L. Wang, X. Peng, C. A. Lewis, J. R. Varcoe and W. E. Mustain, J. Power Sources, 2018, 375, 205-213.

26 T. J. Omasta, A. M. Park, J. M. LaManna, Y. Zhang, X. Peng, L. Wang, D. L. Jacobson, J. R. Varcoe, D. S. Hussey, B. S. Pivovar and W. E. Mustain, Energy Environ. Sci., 2018, 11, 551-558.

27 L. Wang, J. J. Brink and J. R. Varcoe, Chem. Commun., 2017, 53, 11771-11773.

28 J. Ponce-González, I. Ouachan, J. R. Varcoe and D. K. Whelligan, J. Mater. Chem. A, 2018, 6, 823-827.

29 L. Wang, E. Magliocca, E. L. Cunningham, W. E. Mustain, S. D. Poynton, R. Escudero-Cid, M. M. Nasef, J. PonceGonzález, R. Bance-Souahli, R. C. T. Slade, D. K. Whelligan and J. R. Varcoe, Green Chem., 2017, 19, 831-843.

30 J. Ponce-Gonzalez, D. K. Whelligan, L. Wang, R. BanceSoualhi, Y. Wang, Y. Peng, H. Peng, D. C. Apperley, H. N. Sarode, T. P. Pandey, A. G. Divekar, S. Seifert, A. M. Herring, L. Zhuang and J. R. Varcoe, Energy Environ. Sci., 2016, 9, 3724-3735.

31 www.agcce.com/brochurespdfs/sales/FluonGrades.pdf, accessed 2018-08-14.

32 S. J. Normile, D. C. Sabarirajan, O. Calzada, V. de Andrade, X. Xiao, P. Mandal, D. Y. Parkinson, A. Serov, P. Atanassov and I. V. Zenyuk, Materials Today Energy, 2018, 9, 187-197.

33 L. Wang, M. Bellini, H. A. Miller and J. R. Varcoe, J. Mater. Chem. A, 2018, 6, 15404-15412.

34 A. Zadick, L. Dubau, N. Sergent, G. Berthoméand and M. Chatenet, ACS Catal., 2015, 5, 4819-4824.

35 A. Serov, I. V. Zenyuk, C. G. Arges and M. Chatenet, J. Power Sources, 2018, 375, 149-157.

36 S. Gottesfeld, D. R. Dekel, M. Page, C. Bae, Y. Yan, P. Zelenay and Y. S. Kim, J. Power Sources, 2018, 375, 170-184.

37 D. R. Dekel, S. Willdorf, U. Ash, M. Amar, S. Pusara, S. Dhara, S. Srebnik and C. E. Diesendruck, J. Power Sources, 2018, 375, 351-360.

38 L. Wang, J. J. Brink, Y. Liu, A. M. Herring, J. Ponce-Gonzalez, D. K. Whelligan and J. R. Varcoe, Energy Environ. Sci., 2017, 10, 2154-2167. 